\title{
Analysis of Employee Patient Portal Use and Electronic Health Record Access at an Academic Medical Center
}

\author{
Lina Sulieman $^{1} \quad$ Bryan Steitz $^{1} \quad$ S. Trent Rosenbloom ${ }^{1}$ \\ ${ }^{1}$ Department of Biomedical Informatics, Vanderbilt University \\ Medical Center, Nashville, Tennessee, United States \\ Address for correspondence Lina Sulieman, PhD, Department of \\ Biomedical Informatics, Vanderbilt University Medical Center, 2525 \\ West End Avenue, Suite 1400, Nashville, TN 37203, United States \\ Appl Clin Inform 2020;11:433-441. \\ (e-mail: Sulieman.lina@gmail.com).
}

Abstract

Keywords

- patient engagement

- patient portals

- electronic health records
Background Patient portals provide patients and their caregivers online access to limited health results. Health care employees with electronic health record (EHR) access may be able to view their health information not available in the patient portal by looking in the EHR.

Objective In this study, we examine how employees use the patient portal when they also have access to the tethered EHR.

Methods We obtained patient portal and EHR usage logs corresponding to all employees who viewed their health data at our institution between January 1, 2013 and November 1, 2017. We formed three cohorts based on the systems that employees used to view their health data: employees who used the patient portal only, employees who viewed health data in the EHR only, and employees who used both systems. We compared system accesses and usage patterns for each employee cohort.

Results During the study period, 35,172 employees accessed the EHR as part of patients' treatment and 28,631 employees accessed their health data: 25,193 of them used the patient portal and 13,318 accessed their clinical data in EHR. All employees who accessed their records in the EHR viewed their clinical notes at least once. Among EHR accesses, clinical note accesses comprised more than $42 \%$ of all EHR accesses. Provider messaging and appointment scheduling were the most commonly used functions in the patient portal. Employees who had access to their health data in both systems were more likely to engage with providers through portal messages.

Conclusion Employees at a large medical center accessed clinical notes in the EHR to obtain information about their health. Employees also viewed other health data not readily available in the patient portal.

\section{Background and Significance}

Health care organizations commonly offer patients online access to their health information through patient portals. Patient portals commonly allow individuals to access and review selected health information, ${ }^{1-6}$ communicate with health care providers, ${ }^{7-11}$ manage their medications, ${ }^{12}$ upload their laboratory results, ${ }^{13}$ and complete medical and adminis- trative forms. ${ }^{14}$ Patient portal adoption has increased recently, likely in response to consumer demand, regulatory incentives, and evidence that they improve care. ${ }^{15-18}$ Further, a report by the National Academy of Medicine promotes patient portal access as means to improve patient engagement and education and to help patients manage their health and their children. ${ }^{19-25}$ Patient portal use has been shown to correlate with improved disease and medication management, increased received

December 19, 2019

accepted

May 14, 2020 (c) 2020 Georg Thieme Verlag KG Stuttgart . New York
DOI https://doi.org/ 10.1055/s-0040-1713412. ISSN 1869-0327. 
patient satisfaction, and improved clinical outcomes for patients with chronic disease. . $^{8,20,21,26-35}$

There currently does not exist a widely accepted standard directing which electronic medical record data should be made available to patient portal users, or when it should be released. One of the major types of clinical information components that electronic health records (EHRs) include and almost all patient portals lack is clinical notes. The Office of National Coordinator for Health Information, implementing the 21st Century Cure Act, ruled to provide patients access to all their information in EHR including clinical notes. ${ }^{36-38}$ In response, OpenNotes has arisen as a national initiative that encourages sharing patients' entire EHRs-including clinical notes-via patient portals. ${ }^{39-41}$ Studies of OpenNotes have evaluated the patients' understanding of their health conditions, recalling care plans, and participation in shared decision making. ${ }^{42,43}$ In one study to evaluate granting access to minority patients to read their clinical notes, authors found that black, Hispanic, and Asian patients indicated that reading notes was highly important. ${ }^{43}$ Another study found that patients who read at least four clinical notes in a year were more likely to be involved in the decision-making process of their care plan. ${ }^{44}$ Despite the growing body of research indicating the safety and effectiveness of sharing clinical notes into patient portals-including full OpenNotes implementationmost health systems have not yet adopted this approach. ${ }^{45}$ As a result, practices around content and timing for health data sharing in patient portals vary. ${ }^{46}$

We hypothesized that individuals with routine access to EHRs would look up their own personal health data in the EHR when the data (i.e., clinical notes) are unavailable in the tethered patient portal. Numerous health care institutions, including our institution, allow their employees to access their own personal health data via the EHR after submitting an authorization form. ${ }^{4-53}$ For instance, the policy in our institutions states that: "Workforce member who by virtue of his or her assigned job role has been granted authorized access to the electronic medical record may access and view his or her own medical record and the electronic medical records of their minor children for whom they are the legal guardian." Those employees who have access to EHR can view notes, images, and all other information that does not exist in the patient portal. We are unaware of existing research evaluating how health system employees access their own health data.

\section{Objective}

In this study, we measured how employees with routine jobrelated access to the institutional EHR at a large academic medical center viewed their own health data when the tethered patient portal did not provide complete access to their medical records. With the growing interest in patient engagement, health data sharing, and OpenNotes, studies characterizing how individuals access their own records when unavailable in the patient portal can guide policy and practice. We assessed specific functions used in the EHR and the patient portal across three cohorts: employees who used the patient portal only, employees who viewed health data in the EHR only, and employees who used both systems.

\section{Methods}

\section{Study Setting}

This study was conducted at Vanderbilt University Medical Center (VUMC), a large academic medical center located in middle Tennessee. VUMC includes 834-bed adult's hospital, 271-bed children's hospital, and outpatient clinics throughout the state. During the study period, our medical center offered an institutionally developed patient portal, My Health at Vanderbilt (MHAV), which allowed patients who receive care at VUMC to access selected data from their EHR. MHAV also offered common patient portal features, including viewing laboratory test results, viewing medications, and sending messages to health care providers. ${ }^{16,28}$ MHAV was launched in 2003 and its implementation expanded across all clinical specialties beginning in 2007. MHAV and the tethered EHR were certified for Meaningful Use Stages 1 and 2. MHAV displays laboratory and testing results at different times following their completion based on the sensitivity of the test but does not generally make clinical notes available. Throughout the time of this study, VUMC treated 1,347,393 patients across inpatient and outpatient settings. Among those patients, $31.7 \%$ of those age 18 years old or over actively used MHAV during the study period. In addition, by institutional policy, employees with routine jobrelated clinical access to the EHR for their clinical duties were permitted to review their own medical records in the EHR.

\section{Study Period and Population}

This study compared three cohorts of employees' personal access to their medical records during the study period from August 1, 2013 through November 1, 2017. These three cohorts represented employees who used just MHAV (MHAV only) to view their records, employees who used just the EHR to view their own records (EHR only), and employees who accessed both MHAV and the EHR system to view their records (MHAV \& EHR). The Institutional Review Board (IRB) approval for this study covered all MHAV users and all VUMC employees who accessed their health data. We examined MHAV access logs for all usage during the study period. Access logs contained information about which MHAV functions were used, a unique patient identifier, and a time stamp. We then classified each unique patient identifier by VUMC employment status. We also extracted EHR access logs for all employees who accessed their own health records during the study period. Each access log included a unique patient identifier, a time stamp, and an access action description. For each employee, we obtained the job title, patient identifier, and employment identifier. Authors extracted the job titles from VUMC employees' records, then classified each employee into one of nine groups based on their job title (Box 1). This study was performed in compliance with the World Medical Association Declaration of Helsinki on Ethical Principles for Medical Research Involving Human Subjects, and was reviewed by the VUMC IRB. 


\section{Box 1 Employee job classifications}

Administrators: Individuals who perform nonclerical duties (coding specialists, administrative assistants, etc.)

Billing Provider: Billing providers with a medical or similar degree (e.g., Doctor of Medicine, Doctor of Osteopathic Medicine, physician assistant, etc.)

Medical Assistant: Individuals who support physicians and nurses in their clinical duties, but have not completed a nursing training program

Nurse: Employees who have completed a nursing training program (e.g., Licensed Practical Nurse, Registered Nurse, etc.)

Researcher: Individuals who perform both clinical and nonclinical investigations (e.g., graduate students, research assistants, scientists)

Staff: Individuals who perform clerical duties at a specific clinic

Student: Individuals in a medical training program who have not yet received their intended degree (e.g., medical, nursing, etc.)

Technician: Employees who perform technical, mechanical, or diagnostic tests in a medical environment (e.g., pharmacy technician, laboratory technician, etc.)

Other: Individuals not classified in any of the above classifications

\section{Data Analysis}

We aggregated VUMC and EHR access events into function categories, summarized in Box 2, to compare the usage between systems by user role and access cohort. First, we calculated descriptive statistics to compare user demographics by access cohort. To evaluate function use in VUMC and the EHR, we compared proportions of employees who used each respective function in both systems to access their own health records. We applied proportion tests and Fisher's tests to assess significance

Box 2 The documents' types and function accesses in electronic health record (EHR) and patient portal (PP)

\section{EHR events \\ Documents: Visit notes, histories, discharge summaries, operative notes, procedure notes, consultations, reports, postoperative notes, instructions, assessments, patient ed- ucation, clinical intake \\ Messages: Provider-provider and patient-provider commu- nications \\ Laboratory Tests: View results from previously ordered lab- oratory tests \\ Medications: Medications and immunizations \\ Images: Images, videos, scans, waveform data \\ Encounters: Appointments, admissions \\ Orders: Medication orders, radiology, images, laboratory tests \\ Other: Any document that did not fit in the above categories MHAV events \\ Appointment: Request appointment, view online appoint- ment schedule, view visit summaries \\ Messaging: View, send, forward, or delete a secure message with a provider \\ Laboratories: View laboratories, vitals, or reports \\ Medication: View current medications and immunizations}

Note: We grouped similar accesses and events into eight EHR functions and four My Health at Vanderbilt (MHAV) functions. between access cohorts and user roles. We applied a generalized linear model (GLM), fit on system type and employee role to test the overall proportional difference in function access. We analyzed access of shared functionality between systems by user role and access cohort, using a proportion test and GLM to statistically compare differences by user role and access cohort. We performed statistical analysis using $R^{54}$

\section{Results}

Over the course of the study period, 35,172 unique employees worked at VUMC and had access to the EHR. Among these, 28,631 (79.4\%) accessed their health records in MHAV and/or the EHR. There were a total of 25,193 (87.9\%) employees who accessed their health data in MHAV. Despite the availability of MHAV, 13,318 out of 28,631 (46.5\%) accessed their health data in the EHR; and 9,880 (34.5\%) accessed their health data in both MHAV and the EHR. - Table 1 provides demographics across the entire population and each access cohort. The majority of employees included in the study were female (73.8\%) and Caucasian (74.1\%). Employees who accessed only MHAV were, on average, 11 years younger than employees who accessed their data only in the EHR. - Table 2 shows the distribution of job titles across access groups. Nurses had the highest number of users with 9,595 in the three function access groups with a defined job description. Employees collectively accessed their health data through MHAV and the EHR 2,795,884 and 3,341,036 times, respectively. Employees who accessed both systems were more active than those who only accessed one system, making up 54\% of all MHAV accessions and 85\% of all EHR accessions identified for this study (proportion test $p<0.0001$ ).

-Fig. 1 presents the percentage of employees who accessed MHAV functions. Employees used secure messaging more than other MHAV functions, with accesses by 63.6 to $87.2 \%$ of employees who used the patient portal only, and 80.2 to $92.4 \%$ of employees in the MHAV \& EHR cohort (see - Table S1 in the - Supplementary Appendix, available in the online version).

We present the percentage of patients who used EHR functions in - Fig. 2. Using the EHR, all employees viewed their clinical documents and 99.6\% of employees accessed their orders. We report the percentages of EHR actions for employees who accessed MHAV \& EHR and accessed EHR only in -Table $\mathbf{2} 2$ in the - Supplementary Appendix (available in the online version).

In - Table 3, we show access patterns for shared functionality in the EHR and MHAV, by user role. Employees cannot send or view messages to their providers via EHR; however, they can view the messages sent by their care team. We considered MHAV messages and EHR message baskets as similar functions. Employees commonly used MHAV to exchange messages (63-90\%) and view appointments (50-86\%). The EHR was most commonly used to access medications (60-84\%) and to access laboratory results (51-84\%). The most common functions in MHAV (messaging) and EHR (viewing notes) were the same in the three groups: employees who accessed their MHAV only, EHR only, and both EHR and MHAV. 
Table 1 Demographics of employees who accessed their health record via only PP, only EHR, and both MHAV and EHR

\begin{tabular}{|c|c|c|c|c|}
\hline & $\begin{array}{l}\text { Only MHAV } \\
(n=15,313)\end{array}$ & $\begin{array}{l}\text { Only EHR } \\
(n=3,438)\end{array}$ & $\begin{array}{l}\text { MHAV and EHR } \\
(n=9,880)\end{array}$ & $\begin{array}{l}\text { Not accessed own record } \\
(n=6,541)\end{array}$ \\
\hline \multicolumn{5}{|l|}{ Gender } \\
\hline Female (\%) & $10,717(70.0)$ & $2,494(72.5)$ & $7,921(80.2)$ & 4,793 (73.3) \\
\hline Male (\%) & 4,584 (29.9) & $940(27.3)$ & 1,957 (19.8) & $1,731(26.5)$ \\
\hline Unknown (\%) & $12(0.1)$ & $4(0.1)$ & $2(0.0)$ & $17(26)$ \\
\hline \multicolumn{5}{|l|}{ Race } \\
\hline White (\%) & $10,884(71.1)$ & $2,389(69.5)$ & $7,947(80.4)$ & $3,956(60.5)$ \\
\hline Black (\%) & $1,317(8.6)$ & $507(14.7)$ & $1,058(10.7)$ & $823(12.6)$ \\
\hline Asian (\%) & $690(4.5)$ & $84(2.4)$ & $391(4.0)$ & $185(2.8)$ \\
\hline Indigenous (\%) & $25(0.2)$ & $4(0.1)$ & $24(0.2)$ & $13(19.9)$ \\
\hline Unknown (\%) & $2,397(15.7)$ & $454(13.2)$ & $460(4.7)$ & $1,564(23.9)$ \\
\hline \multicolumn{5}{|l|}{ Ethnicity } \\
\hline Hispanic (\%) & $413(2.7)$ & $59(1.7)$ & 289 (2.9) & $137(2.1)$ \\
\hline Non-Hispanic (\%) & $14,900(97.3)$ & $3,379(98.3)$ & $9,591(97.1)$ & $6,404(97.9)$ \\
\hline \multicolumn{5}{|l|}{ Age } \\
\hline Mean & 37.6 & 48.5 & 43.9 & 44.6 \\
\hline
\end{tabular}

Abbreviations: EHR, electronic health record; MHAV, My Health at Vanderbilt; PP, patient portal.

Note: $p$-Values for chi-square and Fisher's (when cell values 5 or lower) tests were $<0.00001$ for gender and race, and $<0.001$ for ethnicity. $t$-Test was $<0.00001$ for age.

Table 2 The number of employees grouped by their role in each function access group

\begin{tabular}{|c|c|c|c|c|c|}
\hline & MHAV and EHR & Only EHR & Only MHAV & Not accessed EHR or MHAV & Total \\
\hline Technician & $558(26.2 \%)$ & $120(5.6 \%)$ & $393(18.5 \%)$ & $1,058(49.7 \%)$ & 2,129 \\
\hline Staff & $306(45.8 \%)$ & $0(0 \%)$ & $48(7.2 \%)$ & $314(47.0 \%)$ & 668 \\
\hline Student & 349 (35.1\%) & $189(19.0 \%)$ & $242(24.3 \%)$ & $215(21.6 \%)$ & 995 \\
\hline Nurse & $2,782(38.8 \%)$ & $877(12.2 \%)$ & $1,669(23.3 \%)$ & $1,842(25.7 \%)$ & 7,170 \\
\hline Physician & $1,354(39.3 \%)$ & $603(17.5 \%)$ & $443(12.8 \%)$ & $1,049(30.4 \%)$ & 3,449 \\
\hline Medical assistant & $221(55.4 \%)$ & $79(19.8 \%)$ & $56(14.0 \%)$ & $4310.8 \%)$ & 399 \\
\hline Research & $144(42.0 \%)$ & $0(0 \%)$ & $51(14.9 \%)$ & $148(43.1 \%)$ & 343 \\
\hline Admin & 107 (14.1\%) & $79(10.4 \%)$ & $86(11.3 \%)$ & $489(64.3 \%)$ & 761 \\
\hline Other & $4,059(21.1 \%)$ & $1,491(7.7 \%)$ & $12,325(64.0 \%)$ & $1,383(7.2 \%)$ & 19,258 \\
\hline Total & 9,880 & 3,438 & 15,313 & 6,541 & 35,172 \\
\hline
\end{tabular}

Abbreviations: EHR, electronic health record; MHAV, My Health at Vanderbilt.

\section{Discussion}

This study characterized how employees with access to their EHRs use a patient portal and the EHR to access their health records. During our study period, $34.5 \%$ of employees used both the EHR and MHAV to access their health data. Our findings revealed that the types of accessed information differed by system. Employees commonly used the EHR to view clinical documents and orders-the data types not available in our patient portal, but still used the patient portal to communicate electronically with their providers. Employees who were not licensed clinicians or trainees (i.e., nonphysician employees, nurses, medical assistants, and medical students) reviewed their laboratory results and orders in the EHR and communicated more with their health care provider via the patient portal.

Of interest, all employees who accessed their EHR in our study viewed their clinical notes at least once. This was true even for employees without clinical training, who read their documents at high rates. Studies have demonstrated that reading clinical notes can be essential to understanding the health condition and care plans, and encouraging patients' engagement in their decision making regardless of having a medical degree. ${ }^{42,44}$ Employees who accessed only the EHR and did not have a MHAV account still viewed their notes more than any other document in the EHR. Although they did not message their providers through our studied information systems, they read the messages sent between care team 


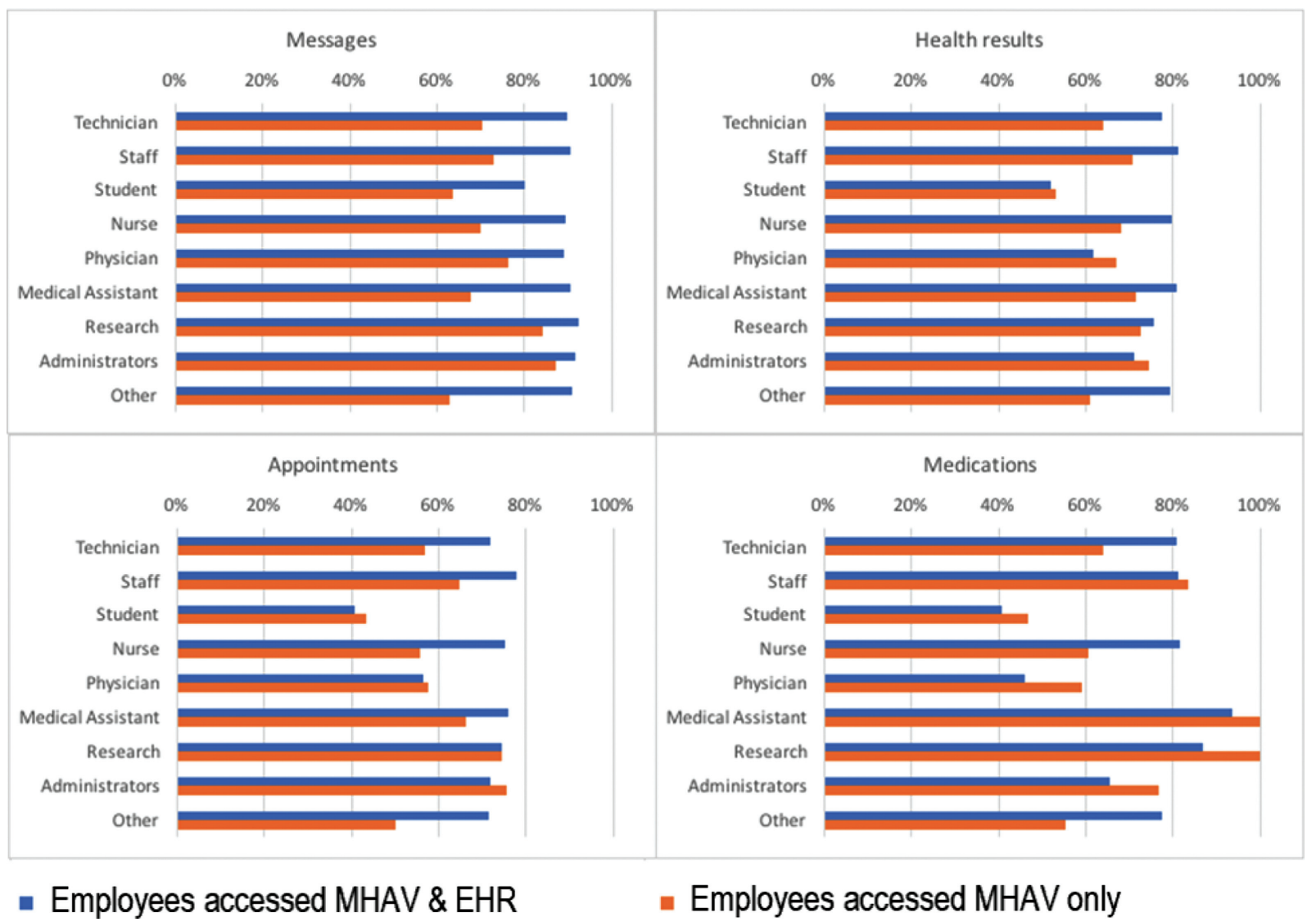

Fig. 1 Percentages of employees who accessed each My Health at Vanderbilt (MHAV) functions for employees who accessed their health data in MHAV and electronic health record (EHR) and employees who only accessed the MHAV.

members. Our results showed that employees in health care realized the relevance and the importance of accessing their clinical notes. ${ }^{55}$ Despite the access to MHAV, some employees accessed their EHR to seek their health information that the portal lacked. Providing notes to patients have the same degree of relevance and can improve the breadth and depth of clinical data available for patients.

Employees who accessed their health data through both the EHR and MHAV sent more patient portal messages than employees who accessed MHAV only. Similarly, employees who accessed both systems, with the exception of administrators and physicians, were more likely to review their laboratory results through the patient portal. We hypothesize that the limited view of health information through the patient portal might contribute to this decreased messaging use among employees who only used MHAV. Alternatively, these results could also suggest that employees who accessed both systems may be more engaged in their health care than those who only viewed data presented in the patient portal. Although some health care institutions fear that sharing notes with patients or granting access to their employees might be alarming or worrisome, the literature of current initiatives for sharing medical data with patients stated that the benefits outweigh the risks. Future work should assess how the addition of health results, including clinical notes, in the patient portal contributes to messaging utilization among users.
Our study is not without limitations. Our data come from a single academic medical center with an internally developed patient portal and EHR system, which may limit generalizability of the findings to other institutions. However, the EHR system and tethered patient portal were certified for Meaningful Use Stage 2 and have functions similar to many other commercial EHR and patient portal systems. Second, we conducted our study in an organization that allows its employees to view their records. We recognize that some organizations may have policies that prohibit their employees from accessing their own health records. However, we did not find any published instances of these access restrictions in our literature review or evidence of a clear and widely adopted standard regarding health center employees accessing their own health data via the EHR. Similarly, our study focused on the type of clinical documents that patients viewed in the EHR, when given access. We do not attempt to analyze the implications of a policy of granting employees access their EHR. Third, our analysis focused on use of a core set of functionalities, which is available in most common patient portals and EHR systems. Additionally, our study did not account for temporality in system access. We similarly did not have access to other patient-specific health care utilization measures, such as telephone calls, ambulatory visits, or inpatient admissions. Our ongoing research is investigating patient-specific clinical and health care utilization statistics on patient portal use. 


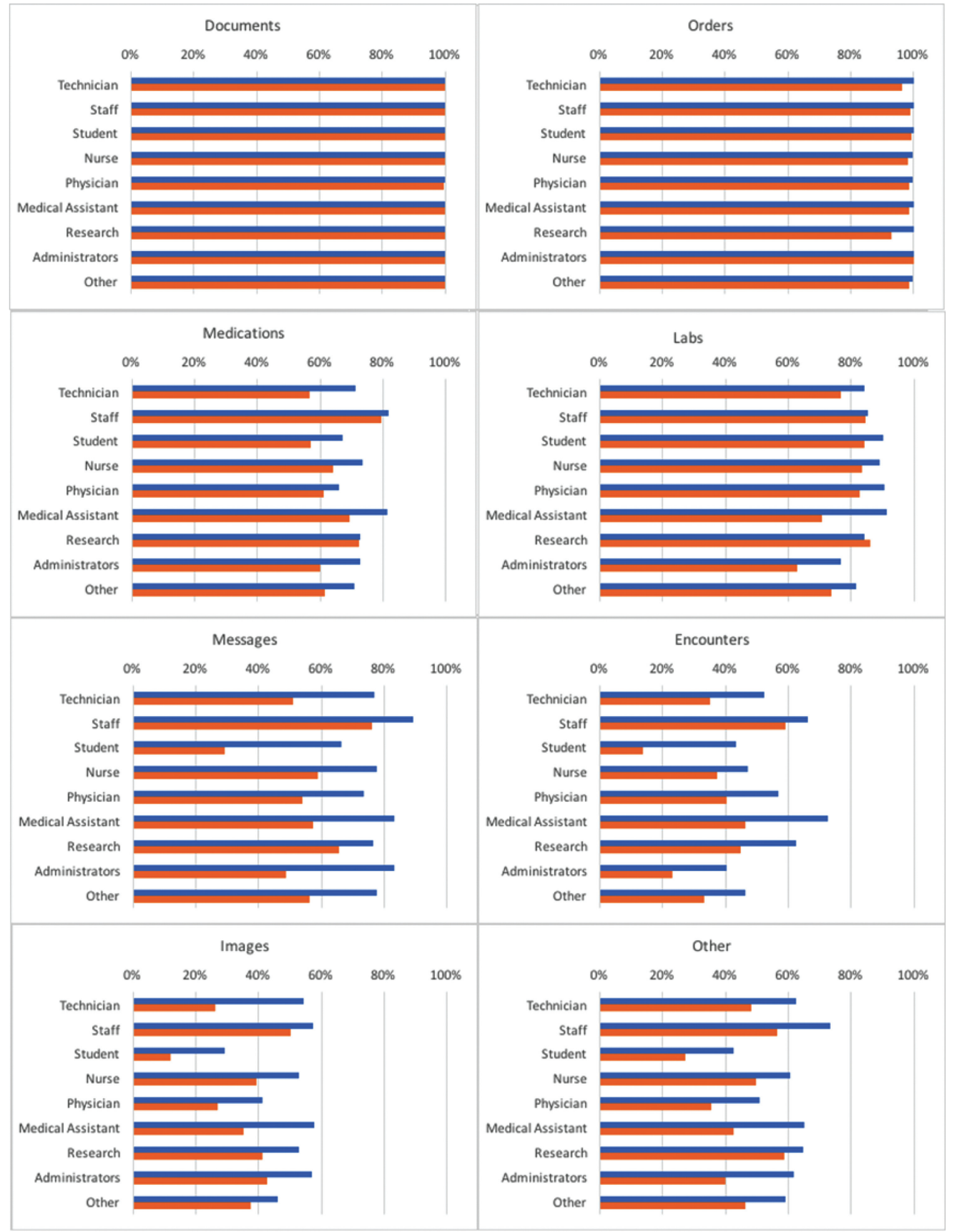

- Employees accessed MHAV \& EHR

- Employees accessed EHR only

Fig. 2 Percentages of employees who accessed each electronic health record (EHR) functions for employees who accessed their health data in both My Health at Vanderbilt (MHAV) and EHR and employees who only accessed the EHR.

\section{Conclusion}

To our knowledge, this is one of the first studies to investigate how employees at an academic medical center access their health data through the EHR system and the patient portal.
We found that employees with access to the EHR commonly view their clinical documents and orders. Employees who access the patient portal commonly use secure messaging functionality. Despite recent initiatives, such as OpenNotes, to incorporate clinical documents into the patient portal, 
Table 3 The proportions of MHAV function accesses in both MHAV and EHR

\begin{tabular}{|c|c|c|}
\hline & $\begin{array}{l}\text { MHAV accesses } \\
\text { proportion for } \\
\text { employees } \\
\text { accessed } \\
\text { any system } \\
n=28,631\end{array}$ & $\begin{array}{l}\text { MHAV accesses } \\
\text { proportion in } \\
\text { MHAV and EHR } \\
n=9,880\end{array}$ \\
\hline Technician & $n=1,126$ & $n=558$ \\
\hline Laboratory & $57.1 \%$ & $52.1 \%^{\mathrm{a}}$ \\
\hline Medication & $39.2 \%$ & $33.4 \%^{\mathrm{a}}$ \\
\hline Messages & $83.9 \%$ & $80.6 \%^{\mathrm{a}}$ \\
\hline Appointment & $78.9 \%$ & $76.0 \%^{\mathrm{a}}$ \\
\hline Staff & $n=471$ & $n=306$ \\
\hline Laboratory & $27.0 \%$ & $29.9 \%^{a}$ \\
\hline Medication & $16.3 \%$ & $28.0 \%^{\mathrm{a}}$ \\
\hline Messages & $63.3 \%$ & $66.9 \%^{a}$ \\
\hline Appointment & $50.4 \%$ & $62.3 \%^{a}$ \\
\hline Student & $n=782$ & $n=349$ \\
\hline Laboratory & $34.3 \%$ & $24.7 \%^{\mathrm{a}}$ \\
\hline Medication & $36.5 \%$ & $30.0 \%^{a}$ \\
\hline Messages & $87.6 \%$ & $83.4 \%^{\mathrm{a}}$ \\
\hline Appointment & $72.6 \%$ & $60.4 \%^{\mathrm{a}}$ \\
\hline Nurse & $n=5,320$ & $n=2,782$ \\
\hline Laboratory & $49.3 \%$ & $43.6 \%^{\mathrm{a}}$ \\
\hline Medication & $34.6 \%$ & $30.1 \%^{\mathrm{a}}$ \\
\hline Messages & $82.3 \%$ & $80.4 \%^{\mathrm{a}}$ \\
\hline Appointment & $75.7 \%$ & $75.1 \%$ \\
\hline Physician & $n=2,461$ & $n=1,354$ \\
\hline Laboratory & $28.9 \%$ & $26.4 \%^{\mathrm{a}}$ \\
\hline Medication & $27.8 \%$ & $27.3 \%$ \\
\hline Messages & $84.4 \%$ & $85.1 \%^{\mathrm{a}}$ \\
\hline Appointment & $63.3 \%$ & $65.7 \%^{\mathrm{a}}$ \\
\hline Assistant & $n=359$ & $n=221$ \\
\hline Laboratory & $40.7 \%$ & $38.0 \%^{\mathrm{a}}$ \\
\hline Medication & $27.8 \%$ & $26.0 \%$ \\
\hline Messages & $74.8 \%$ & $75.6 \%$ \\
\hline Appointment & $60.8 \%$ & $68.0 \%^{\mathrm{a}}$ \\
\hline Research & $n=224$ & $n=144$ \\
\hline Laboratory & $53.2 \%$ & $43.3 \%^{\mathrm{a}}$ \\
\hline Medication & $41.0 \%$ & $31.5 \%^{\mathrm{a}}$ \\
\hline Messages & $85.2 \%$ & $82.4 \%^{\mathrm{a}}$ \\
\hline Appointment & $76.8 \%$ & $72.6 \%^{\mathrm{a}}$ \\
\hline Administrators & $n=228$ & $n=107$ \\
\hline Laboratory & $56.9 \%$ & $48.2 \%^{\mathrm{a}}$ \\
\hline Medication & $34.3 \%$ & $24.3 \%^{\mathrm{a}}$ \\
\hline Messages & $85.8 \%$ & $81.4 \%^{\mathrm{a}}$ \\
\hline Appointment & $81.4 \%$ & $73.7 \%^{a}$ \\
\hline
\end{tabular}

(Continued)
Table 3 (Continued)

\begin{tabular}{|c|l|l|}
\hline & $\begin{array}{l}\text { MHAV accesses } \\
\text { proportion for } \\
\text { employees } \\
\text { accessed } \\
\text { any system } \\
\boldsymbol{n}=\mathbf{2 8 , 6 3 1}\end{array}$ & $\begin{array}{l}\text { MHAV accesses } \\
\text { proportion in } \\
\text { MHAV and EHR } \\
\boldsymbol{n}=\mathbf{9 , 8 8 0}\end{array}$ \\
\hline Other & $n=17,660$ & $n=4,059$ \\
\hline Laboratory & $70.4 \%$ & $45.9 \%^{\mathrm{a}}$ \\
\hline Medication & $56.3 \%$ & $33.2 \%^{\mathrm{a}}$ \\
\hline Messages & $89.7 \%$ & $81.1 \%^{\mathrm{a}}$ \\
\hline Appointment & $85.6 \%$ & $73.3 \%^{\mathrm{a}}$ \\
\hline
\end{tabular}

Abbreviations: EHR, electronic health record; MHAV, My Health at Vanderbilt.

Note: Functions are grouped for matching action in MHAV and EHR. The significance of $p$-value of the proportion test between MHAV proportions of MHAV and EHR accesses for employees accessed any or both system and MHAV proportions for employees in MHAV and EHR are shown by a superscript alphabet next to the it. We adjusted for the multiple comparisons when we reported the significance. Any p-value that exceeded the corrected threshold does not have a superscript alphabet next to it which indicate the insignificance.

${ }^{a} p$-Value less than 0.0001 .

most health systems have not yet adopted this approach. ${ }^{55}$ Our results indicated that all employees, regardless of their training or background, viewed their notes at least once. Providing patients with access to their health data, including notes, is one approach to improve patient engagement and better enable patient-provider communication.

\section{Clinical Relevance Statement}

Our study investigated the types of clinical documents viewed by employees who accessed the patient portal, their electronic health records, or both. The results of the study can guide the importance of granting patients access to their medical information including clinical notes. Acquiring more information can increase patient engagement in their treatment and decision making.

\section{Multiple Choice Questions}

1. In most tethered patient portals, patients cannot access one of the following clinical data:

a. Laboratory test results.

b. Clinical documents.

c. Medications.

d. Immunizations.

Correct Answer: The correct answer is option b, clinical documents. Patient can view their demographics, laboratory test results, medications, and appointments.

2. The action of viewing personal electronic health record by employees is:

a. Always allowed. 

b. Never allowed.
c. Based on organization policy.
d. Partial access provided.

Correct Answer: The correct answer is option c, based on organization policy. Some health care organizations allow their employees to view their own medical records, while other organizations prohibit this action.

Protection of Human and Animal Subjects

This study was submitted to the Institutional Review Board (IRB) Office and did not involve any human subjects. As such, it was exempt from IRB review.

\section{Conflict of Interest}

None declared.

\section{References}

1 Nazi KM, Woods SS, Woods SS. MyHealtheVet PHR: a description of users and patient portal use. AMIA Annu Symp Proc 2008:1182

2 Koonce TY, Giuse DA, Beauregard JM, Giuse NB. Toward a more informed patient: bridging health care information through an interactive communication portal. J Med Libr Assoc 2007;95(01): 77-81

3 Detmer D, Bloomrosen M, Raymond B, Tang P. Integrated personal health records: transformative tools for consumer-centric care. BMC Med Inform Decis Mak 2008;8:45

4 Kaelber D, Pan EC. The value of personal health record (PHR) systems. AMIA Annu Symp Proc 2008:343-347

5 Tsai R, Bell EJ III, Woo H, Baldwin K, Pfeffer MA. How patients use a patient portal: an institutional case study of demographics and usage patterns. Appl Clin Inform 2019;10(01):96-102

6 Grossman LV, Masterson Creber RM, Ancker JS, et al. Technology access, technical assistance, and disparities in inpatient portal use. Appl Clin Inform 2019;10(01):40-50

7 Cronin RM, Davis SE, Shenson JA, Chen Q, Rosenbloom ST, Jackson GP. Growth of secure messaging through a patient portal as a form of outpatient interaction across clinical specialties. Appl Clin Inform 2015;6(02):288-304

8 Goldzweig CL, Towfigh AA, Paige NM, et al. Systematic Review: Secure Messaging Between Providers and Patients, and Patients Access to Their Own Medical Record: Evidence on Health Outcomes, Satisfaction, Efficiency and Attitudes. Washington (DC) Department of Veterans Affairs (US); 2012

9 Masterman M, Cronin RM, Davis SE, Shenson JA, Jackson GP. Adoption of secure messaging in a patient portal across pediatric specialties. AMIA Annu Symp Proc 2017;2016:1930-1939

10 Shenson JA, Cronin RM, Davis SE, Chen Q Jackson GP. Rapid growth in surgeons' use of secure messaging in a patient portal. Surg Endosc 2016;30(04):1432-1440

11 Walker DM, Gaughan A, Fareed N, Moffatt-Bruce S, McAlearney AS. Facilitating organizational change to accommodate an inpatient portal. Appl Clin Inform 2019;10(05):898-908

12 Zhao JY, Song B, Anand E, et al. Barriers, facilitators, and solutions to optimal patient portal and personal health record use: a systematic review of the literature. AMIA Annu Symp Proc 2018;2017:1913-1922

13 Ancker JS, Mauer E, Kalish RB, Vest JR, Gossey JT. Early adopters of patient-generated health data upload in an electronic patient portal. Appl Clin Inform 2019;10(02):254-260

14 Tang PC, Ash JS, Bates DW, Overhage JM, Sands DZ. Personal health records: definitions, benefits, and strategies for overcoming barriers to adoption. J Am Med Inform Assoc 2006;13(02):121-126

15 Neuner J, Fedders M, Caravella M, Bradford L, Schapira M. Meaningful use and the patient portal: patient enrollment, use, and satisfaction with patient portals at a later-adopting center. Am J Med Qual 2015;30(02):105-113

16 Osborn CY, Rosenbloom ST, Stenner SP, et al. MyHealthAtVanderbilt: policies and procedures governing patient portal functionality. J Am Med Inform Assoc 2011;18(Suppl 1):i18-i23

17 Steitz B, Cronin RM, Davis SE, Yan E, Jackson GP. Long-term patterns of patient portal use for pediatric patients at an academic medical center. Appl Clin Inform 2017;8(03):779-793

18 Dalal AK, Dykes P, Samal L, et al. Potential of an electronic health record-integrated patient portal for improving care plan concordance during acute care. Appl Clin Inform 2019;10(03):358-366

19 Carroll JG. Crossing the quality chasm: A new health system for the 21st century. Quality Management in Healthcare 2002;10(04):60-61

20 Wade-Vuturo AE, Mayberry LS, Osborn CY. Secure messaging and diabetes management: experiences and perspectives of patient portal users. J Am Med Inform Assoc 2013;20(03):519-525

21 Kruse CS, Argueta DA, Lopez L, Nair A. Patient and provider attitudes toward the use of patient portals for the management of chronic disease: a systematic review. J Med Internet Res 2015;17(02):e40

22 Irizarry T, Shoemake J, Nilsen ML, Czaja S, Beach S, DeVito Dabbs A. Patient portals as a tool for health care engagement: a mixedmethod study of older adults with varying levels of health literacy and prior patient portal use. J Med Internet Res 2017;19(03):e99

23 Woolf SH, Krist AH, Lafata JE, et al. Engaging patients in decisions about cancer screening: exploring the decision journey through the use of a patient portal. Am J Prev Med 2018;54(02):237-247

24 Bush RA, Vemulakonda VM, Richardson AC, Deakyne Davies SJ, Chiang GJ. Providing access: differences in pediatric portal activation begin at patient check-in. Appl Clin Inform 2019;10(04): 670-678

25 Stein JN, Klein JW, Payne TH, et al. Communicating with vulnerable patient populations: a randomized intervention to teach inpatients to use the electronic patient portal. Appl Clin Inform 2018;9(04):875-883

26 McAlearney AS, Fareed N, Gaughan A, MacEwan SR, Volney J, Sieck CJ. Empowering patients during hospitalization: perspectives on inpatient portal use. Appl Clin Inform 2019;10(01):103-112

27 Ali SB, Romero J, Morrison K, Hafeez B, Ancker JS. Focus section health IT usability: applying a task-technology fit model to adapt an electronic patient portal for patient work. Appl Clin Inform 2018;9(01):174-184

28 Osborn CY, Mayberry LS, Wallston KA, Johnson KB, Elasy TA. Understanding patient portal use: implications for medication management. J Med Internet Res 2013;15(07):e133

29 Lin CT, Wittevrongel L, Moore L, Beaty BL, Ross SE. An Internetbased patient-provider communication system: randomized controlled trial. J Med Internet Res 2005;7(04):e47

30 Ross SE, Moore LA, Earnest MA, Wittevrongel L, Lin CT. Providing a web-based online medical record with electronic communication capabilities to patients with congestive heart failure: randomized trial. J Med Internet Res 2004;6(02):e12

31 Krist $\mathrm{AH}$, Woolf $\mathrm{SH}$, Rothemich SF, et al. Interactive preventive health record to enhance delivery of recommended care: a randomized trial. Ann Fam Med 2012;10(04):312-319

32 Wright A, Poon EG, Wald J, et al. Randomized controlled trial of health maintenance reminders provided directly to patients through an electronic PHR. J Gen Intern Med 2012;27(01):85-92

33 Green BB, Cook AJ, Ralston JD, et al. Effectiveness of home blood pressure monitoring, Web communication, and pharmacist care on hypertension control: a randomized controlled trial. JAMA 2008;299(24):2857-2867

34 Ralston JD, Hereford J, Carrell D. Use and satisfaction of a patient Web portal with a shared medical record between patients and providers. AMIA Annu Symp Proc 2006:1070

35 Tang PC, Overhage JM, Chan AS, et al. Online disease management of diabetes: engaging and motivating patients online with enhanced resources-diabetes (EMPOWER-D), a randomized controlled trial. J Am Med Inform Assoc 2013;20(03):526-534 
36 ONC Office of the National Coordinator for Health Information Technology (ONC). ONC's Cures Act Final Rule supports seamless and secure access, exchange, and use of electronic health information. Available at: https://www.healthit.gov/curesrule/. Accessed April 11, 2020

37 The Office of the National Coordinator for Health Information Technology (ONC). United States Core Data for Interoperability (USCDI). Available at: https://www.healthit.gov/isa/unitedstates-core-data-interoperability-uscdi. Accessed April, 11, 2020

38 U.S. Food and Drug Administration (FDA). 21st Century Cures Act. Available at: https://www.fda.gov/regulatory-information/selected-amendments-fdc-act/21st-century-cures-act. Accessed April 11, 2020

39 Delbanco T, Walker J, Bell SK, et al. Inviting patients to read their doctors' notes: a quasi-experimental study and a look ahead. Ann Intern Med 2012;157(07):461-470

40 Walker J, Darer JD, Elmore JG, Delbanco T. The road toward fully transparent medical records. N Engl J Med 2014;370(01):6-8

41 Klein JW, Peacock S, Tsui JI, O'Neill SF, DesRoches CM, Elmore JG. Perceptions of primary care notes by patients with mental health diagnoses. Ann Fam Med 2018;16(04):343-345

42 Gerard M, Chimowitz H, Fossa A, Bourgeois F, Fernandez L, Bell SK. The importance of visit notes on patient portals for engaging less educated or nonwhite patients: survey study. J Med Internet Res 2018;20(05):e191

43 Walker J, Leveille S, Bell S, et al. OpenNotes after 7 years: patient experiences with ongoing access to their clinicians' outpatient visit notes. J Med Internet Res 2019;21(05):e13876

44 Fossa AJ, Bell SK, DesRoches C. OpenNotes and shared decision making: a growing practice in clinical transparency and how it can support patient-centered care. J Am Med Inform Assoc 2018; 25(09):1153-1159

45 Walker J, Meltsner M, Delbanco T. US experience with doctors and patients sharing clinical notes. BMJ 2015;350:g7785
46 Krasowski MD, Grieme CV, Cassady B, et al. Variation in results release and patient portal access to diagnostic test results at an academic medical center. J Pathol Inform 2017;8:45

47 Vanderbilt University Medical Center. Information Privacy and Security. Available at: https://ww2.mc.vanderbilt.edu/InfoPrivacySecurity/17073. Accessed June 21, 2019

48 University of Iowa Medical Center. May I access my own medical record? Available at: https://medcom.uiowa.edu/theloop/announcements/quest-newsletter-may-i-access-my-own-medical-record. Accessed June 21, 2019

49 Washington U of. Workforce Members Privacy, Confidentiality, and Information Security Agreement For Patient, Confidential, Restricted and Proprietary Information. Available at: http://depts. washington.edu/comply/docs/002_F1.pdf. Accessed June 21, 2019

50 University of Chicago. Summary of HIPAA Privacy \& Security Rules. Available at: http://hipaa.bsd.uchicago.edu/Summary of HIPAA Privacy and Security Rules.pdf. Accessed June 21, 2019

51 University of Pittsburgh Medical Center. Privacy and security obligation. Available at: http://www.chp.edu/ /media/chp/about-us/ documents/privacy-and-security-obligations.ashx?la=en. Accessed June 21, 2019

52 Care New England. Accessing Your Own EMR. Available at: https:// www.brown.edu/academics/medical/about/departments/psychiatry-and-human-behavior/training/sites/brown.edu.academics.medical.about.departments.psychiatry-and-human-behavior. training/files/uploads/CNE-PRIV-009 Accessing Your Own EMR. pdf. Accessed June 21, 2019

53 Detroit Medical Center. Employee condfidentiality form. Available at: https://www.dmc.org/for-health-professionals/employee-confidentiality-form. Accessed June 21, 2019

54 R. Available at: https://www.r-project.org/. Accessed May 27, 2020

55 Patel V, Johnson C. Individuals' use of online medical records and technology for health needs. ONC Data Brief. 2018 Apr;40. 